\title{
What's So Special About a Special Issue?
}

WILLIAM E. DOLL JR., Associate Editor

Louisiana State University (US) and University of Victoria (Canada)

When Deborah (Editor-in-Chief), Donna and I (Associate Editors) took leadership of Complicity, we decided, consciously, to stay with the theme developed by Brent Davis and Renata Phelps: "enlarging the space of the possible," moving into "that which cannot currently be conceived as a possibility, or "as Derrida [1992] might put it, to experience and experiment with the possibility of the impossible" (Osberg, 2009, p. vi). The vehicle for moving into this realm of the not-yet-possible was to be, and indeed is, conversation. As complexity theorists, we believe that through conversation - not through debate or dialogue - the new emerges. That is, in debate or dialogue contrary beliefs assert themselves, while in conversation contrary beliefs talk with one another, the differences talk. As I read the Responses, I hear a motley of voices talking with, to, past one another. I hope my Introduction conveys the excitement I feel, and encourages readers to bring forth new ideas as they converse with the article and the Responses .

One voice, while not dealing directly with conversation, does bring into focus listening ${ }^{1}-$ a most necessary ingredient if the differences are to talk with one another. This voice encourages us to be attentive to the present moment of experience, to listen to that moment; indeed to listen to the listening present. Other voices let us hear and see classroom examples of such listening. They introduce us to children actually conversing and conceptualizing. Living the experience of being. Other voices join into this Wittgensteinian quest to look, look, look, see, see, see - into both the Mowat and Davis

${ }^{1}$ Brent Davis (1997) has a fine article on "hermeneutic listening." 
text and also into the classroom activities of young children. What emerges is a problematic: the relation between the models and theories we create and the activities of real, live children conversing with one another over an interesting problem.

These "voicings" are but examples of what we asked conversants to do - not only

to "keep the conversation going" (to use Rorty's felicitous phrase (1979, p. 377) but to extend the ideas presented in the featured article. In short, to converse with the ideas Mowat and Davis present. This is what makes a Special Issue so special - listening to, attending to, conversing with the ideas/conceptions embodied in the articles, in the classrooms.

Mowat and Davis have given us, much with which to converse. Their article is filled with provocative problematics. The main problematics emerging - in a recursive, nonlinear manner (addressed more thoroughly below) - are (i) the nature of complexity, (ii) network theory, (iii) metaphor, and (iv) mathematics and mathematics education, all leading to implications for classroom teaching and curriculum. This is a rich and robust ${ }^{2}$ mélange of issues, intertwined not linear, and our conversants have extended their conversations with these issues to raise even more issues. In short, in wrestling with the issues raised, reflecting on different interpretations put forth, I believe we will "see" that Mowat and Davis have presented us the kind of scholarship which can be truly transformative for educational practice.

\section{The Nature of Complexity}

In broad terms, Mowat and Davis ask us to consider mathematics as a complex system, as a complex unity, with both personal knowings (process) and knowledges produced (products) entwined with one another at various structural levels: personal to formal. This view of mathematics, indeed of any discipline, is rich and valuable, worthy of our attention as readers/educators, and of the scrutiny the conversants have given it. With this system view as a premise, Mowat and Davis bring forth the proposition that network theory, with its hubs and nodes frame, may well be valuable in helping educators understand and work with the teaching of mathematics. This is an intriguing and challenging proposition, one the conversants engage in with both enthusiasm and insights. Specifically, Mowat and Davis use network theory to analyze associations among mathematical concepts, focusing on their embodied nature and their reliance on metaphor. This last statement draws strong reactions.

The idea of looking at a discipline in terms of a system view is one the conversants found valuable. Mowat and Davis draw on Paul Cilliers' listing of ten characteristics he

2 The word "robust" is common in complexity literature. It might be said that the robustness of a dynamical system - its richness of interactions - is the very spirit of the system; it is what gives the system it vitality. In a different venue, Bank of Canada Governor, Mark Carney, in a January interview in the Financial Times, talked of a system (here the world banking system) needing to be "robust to failure." To have the ability to transform itself, a system must be dynamic enough that it can fail; it must exist, to use chaos terms, "near the edge of chaos," far away from the balance of equilibrium. Designing and delivering such a robust curriculum is a fascinating challenge. 
believes make up a complex system (Cilliers, 1998). Valuable as these characteristics are to understanding complexity, one conversant worried about what Mowat and Davis left out in positing these ten characteristics as a full categorization of complexity. Notably, memory, emergence, ethics are not in Mowat and Davis' summary of characteristics. There may well be need for a deeper engagement with complexity. This conversant lists people to read who could help in providing a fuller engagement with complexity. It might well be said, though, that Mowat and Davis do not mean to provide an in-depth engagement with complexity, rather they use the ten characteristics of Cilliers to show that mathematics might well be considered a complex system. This raises another issue: whether one can legitimately describe the formal system of mathematics as complex. Certainly learning mathematics is complex, since all learning is a complex activity. But whether a self-consistent formal system can be described as complex is a quite different issue.

The foregoing comments on the nature of complexity could, but should not, be considered a criticism of the Mowat and Davis article. Rather, it points to the problematics which can and do emerge from conversing with their article. All conversants were enthusiastic about the possibilities inherent in the article. Looking at the essay from a variety of perspectives, has extended the domain of conversation and given journal readers an opportunity to converse not only with the main (or "hub") article but also with responses to the article. Thus, new links are formed, providing alternative (and hence deeper) insights into complexity, mathematics, network theory, metaphors, and ways to help us avoid the seduction of the dream of a single logic, universal and universalizing, so prevalent in past and present methods of teaching.

\section{Network Theory}

As Mowat and Davis say, network theory is a new development (p. 2), one which presents a novel way of understanding structure. It may well be a frame undergirding the various forms of complexity - physical/chemical, biological, human, social - each with its own proportion of emphasis. Network theory - exemplified in airline travel patterns (often a hub-link frame) and electric power grids (sometimes or not more varied in their distribution frame) - examines the various ways in which a group of objects [or nodes of knowledge in a discipline] can be connected. As such, the emphasis is on relations not objects (or facts). This emphasis on relations, so important for complexivists studying a classroom with a complexity lens, brings forth the issue of the operatory structures students have or use. Do we need to be aware of the structures a student uses, especially in solving a math problem? Can we help (should we help?) students develop a variety of operatory structures? Conversing with students can play a large role in dealing with this problematic.

Network structures do not use the linear, hierarchical (flow chart) patterns common to institutional organizations, replicated in course outlines, and unilateral expert-novice teaching patterns. Instead, with metaphorical nodes and links (or hubs and spokes), networks distribute flow over an array of connections. This sense of an array of alternative routes (a major part of Mowat and Davis' argument for considering teaching 
in a new way) has great advantages for the effective flow of information. It also is susceptible to cascading failures when too strong a reliance on a centralized hub frame stops the flow of information (or travel) over a large part of the network. Examples of this abound in airplane travel and in electricity transmission grids. Mowat and Davis suggest that adding a few links (weak links) between clusters of nodes (p. 23) may mitigate this problem. One conversant nicely develops thoughts on weak links. Another raises the practical issue of the addiction to absolutes, certainties characteristic of preadolescent youth. Asking youth to adopt a view of multiple meanings, or multiple pathways is a distinct challenge, even, as Sean Buckreis (2010) points out, with preservice college students studying to be teachers.

\section{Metaphors}

Mowat and Davis, draw heavily on Lakoff and Núñez's (2000) assertion that (i) human ideas, are to a large extent, grounded in sensory-motor experience, and (ii) that metaphorical thought may be necessary for human beings to conceptualize the abstract ideas they use (p. xii), to ground their own ideas about looking at mathematics and mathematics learning in terms of network theory. As Mowat and Davis say,

the network of conceptual domains linked by conceptual metaphors provides a possible structure both for the mathematical understanding of individuals and for mathematical knowledge as a formal discipline. (p. 15)

A number of conversants are worried about the Lakoff and Núnez claim that all of mathematics [sophisticated as well as simple constructs] can be tracked back to bodybased metaphors. A number of counter examples are offered. There is also concern about the singular emphasis on metaphor - the imposing of a master metaphor - as a (the?) way to deal with abstractions. As one says, linguists have long recognized the central importance of metaphor in tandem with metonymy; another plays skillfully with the metonymy-metaphor relationship, asking which is which. Language and semiotics are brought in. Again, the point is not that Mowat and Davis should have done something other than what they did - although footnotes acknowledging some of these issues would not be amiss - but rather to extend the conversation for all of us, to give readers a broader frame to understand the rich problematics Mowat and Davis have set before us.

\section{Mathematics and Mathematics Education}

Mowat and Davis state that "our principal focus in this paper is mathematics understood as a system of ideas or concepts" (p. 7). Virtually all the conversants agree this system view is useful, allowing us to move away from a focus on discrete objects of observation toward their fluid interconnections. Personally, I find this system view both inspiring and generative. The sense of interaction (over time, of transaction), of relationality inherent in this statement, will influence the teaching, I am yet to do. One conversant, while by no means denying a dynamic systems thrust, does ask us to reflect on why we create models and theories? What do we lose? What do we gain? 
Most conversants focus on the mathematics/mathematics education distinction, with the question of just what mathematics is - a golden vision of perfect form, an awesome vision of the way God creates, a weird and wonderful creation born of our yet-to-be recognized abilities? At a more prosaic level, it is an organised body of knowledge, a practice engaged in by mathematicians, a school subject, a cultural object of many meanings, and a language and box of conceptual tools. It is indeed a motley. Considering all this, how does one go about teaching it? Considering its self-referential form, is it unique among disciplines? Again, should it be taught, as opposed to explored, played with, appreciated in its many forms and applications?

If one is to adopt, as teachers do, the teaching mode for mathematics, and wish to use the generative frame Mowat and Davis have proposed, then - speaking of metaphors - a number of practical hurdles must be considered. Indeed negotiated. If the teacher is to be cognizant of students' subjective knowings then there is need to sensitize teachers to how human beings have something come to mind; that is, how connections are made in the moment. Deeply embedded metaphors or reluctance to adopt multiple perspectives, are also real life problems in teaching. Another phrasing of this is how does the teacher aid the student in accepting the value of a process approach that is non-linear and emergent? Finally there is the question, each teacher needs to ask of him or her self: To what degree am I asking my students to be compliant with a model I, not they, have chosen?

As I have said so often in this introduction, this special issue is itself designed not only to enlarge the space of the possible, but to bring forth the possibility of the impossible. We, authors and editors, hope that you and we, as readers, will have our visions and practices of teaching enriched. For such we are indeed indebted to Elizabeth Mowat and Brent Davis.

\section{References.}

Buckreis, S. (2010). Reflections on teaching; Searching for a third space. Unpublished Dissertation, Lousiana State University.

Carney, M. Interview: View from the Top. Financial Times, January 25, 2010.

Cilliers, P. (1998). Complexity and postmodernism. London: Routledge.

Davis, B. (1997). Listening for Differences. Journal for Research in Mathematics Education. 28(3), 355-376

Osberg, D. (2009) Editorial: "Enlarging the space of the possible" around what it means to educate and be educated. Complicity: An International Journal of Complexity and Education 6(1), iii-x

Rorty, R. (1979). Philosophy and the mirror of nature. Princeton: Princeton University Press.

Trueit, D. (2010). Teaching as a Complex Conversation. Paper presented at CSER Shanghai Conference, October, 2010.

(C) Copyright 2010. The author, WILLIAM E. DOLL (JR.), assigns to the University of Alberta and other educational and non-profit institutions a non-exclusive license to use this document for personal use and in courses of instruction provided that the article is used in full and this copyright statement is reproduced. The author also grants a non-exclusive license to the University of Alberta to publish this document in full on the World Wide Web, and for the document to be published on mirrors on the World Wide Web. Any other usage is prohibited without the express permission of the authors. 